\title{
Heterogeneidade dos investidores institucionais: evidências entre companhias não financeiras brasileiras
}

\author{
Camila Veneo Campos Fonseca ${ }^{1}$ \\ Rodrigo Lanna Franco da Silveira ${ }^{2}$ \\ Célio Hiratuka ${ }^{3}$
}

\section{Resumo}

O objetivo deste trabalho é investigar quem são os investidores institucionais atuantes no âmbito corporativo brasileiro, explorando, em particular, o grau de heterogeneidade no histórico de atuação destes agentes a partir de suas principais características e perfil de investimento. Aplicando métodos de classificação e agrupamento, os resultados apontaram a existência de quatro diferentes grupos de investidores institucionais acionistas de corporações não financeiras brasileiras. A heterogeneidade intragrupo foi confirmada. Os investidores institucionais agrupados em dois clusters se aproximam de um perfil caracterizado pela miopia dos investimentos, enquanto os do terceiro (quarto) clusters indicaram ter um perfil menos volátil (conservador).

\section{Palavras-Chave}

Investidores institucionais. Heterogeneidade. Análise de cluster.

\begin{abstract}
The purpose of this study is to identify the institutional investors that operate in the Brazilian corporate market. Taking into account, in particular, their characteristics and investment profile, the research explores the heterogeneity of these investors. Using factor analysis and cluster analysis, results showed the presence of four different groups of institutional investors in the
\end{abstract}

- Este artigo é derivado da tese de doutorado "Ensaios sobre a atuação dos investidores institucionais no mercado acionário brasileiro", apresentada em 2019 à Universidade Estadual de Campinas, Campinas, SP, Brasil. Os autores agradecem as revisões realizadas pelos pareceristas desta revista que muito contribuíram para o aprimoramento do artigo.

1 Professora - Faculdades de Campinas - FACAMP

Endereço: Av. Alan Turing, 805 - Barão Geraldo - Campinas/SP - Brasil - CEP: 13083-898.

E-mail: camila.veneo@facamp.com.br - ORCiD: https://orcid.org/0000-0002-1404-1984

2 Professor - Universidade Estadual de Campinas - Instituto de Economia Endereço: Rua Pitágoras, 353 - Barão Geraldo - Campinas/SP - Brasil - CEP: 13083-857.

E-mail: rlanna@unicamp.br - ORCiD: https://orcid.org/0000-0002-1208-5713

3 Professor - Universidade Estadual de Campinas - Instituto de Economia

Endereço: Rua Pitágoras, 353 - Barão Geraldo - Campinas/SP - Brasil - CEP: 13083-857.

E-mail: celioh@unicamp.br - ORCiD: https://orcid.org/0000-0002-3265-3036

Recebido: 01/04/2019. Aceite: 12/05/2020.

Editor Responsável: Dante Mendes Aldrighi

(c) (i) (\$) Esta obra está licenciada com uma Licença Creative Commons Atribuição-Não Comercial 4.0 Internacional. 
Brazilian non-financial corporations. Intra-group heterogeneity was confirmed. Institutional investors grouped into two clusters suggested a profile characterized by myopic investments, while the third (fourth) cluster showed a less volatile (conservative) profile.

\section{Keywords}

Institutional investors. Heterogeneity. Cluster analysis.

\section{Classificação JEL}

G23 e G3.

\section{Introdução}

No fim do século XX, os investidores institucionais, definidos pela Organização para a Cooperação e Desenvolvimento Econômico (OCDE) como um grupo formado por fundos de investimento, seguradoras e fundos de pensão, tornaram-se os principais gestores das poupanças coletivas. Devido ao elevado volume de recursos mobilizados, tornaram-se agenteschave do sistema financeiro (OCDE 2014). Sua importância é usualmente, mas não exclusivamente, atribuída ao papel de intermediários financeiros e, por consequência, ao fato de figurarem como uma potencial fonte de recursos e liquidez aos mercados financeiros (Miyajima e Shim 2014). Tal papel permite que os investidores institucionais exerçam influência não somente sobre as estratégias de financiamento e investimento das corporações não financeiras (CNF), mas também sobre a dinâmica e o crescimento da própria economia (Lazonick e O’Sullivan 2000; Crotty 2002; Orhangazi 2008; Eriksen e Kvaløy 2010).

Diferente do relativo consenso a respeito da importância dos investidores institucionais, o mesmo não se verifica quando questionado o caráter da influência exercida pelos mesmos sobre as empresas das quais são acionistas. Uma série de pesquisas tem avaliado os efeitos da presença dos investidores institucionais na estrutura de propriedade e controle sobre os indicadores econômico-financeiros das CNF. De um lado, aponta-se para o incentivo ao controle e monitoramento da gestão, com reflexos positivos sobre a estratégia corporativa de longo prazo (Bebchuk et al. 2015; Crane et al. 2016; Bena et al. 2016; Fu et al. 2019). Por outro lado, alguns estudos indicam a assunção de um de perfil caracterizado pela miopia dos investimentos, focado nos retornos a curto prazo e potencialmente lesivo 
à sustentabilidade da empresa investida (Bushee 2004; Eriksen e Kvaløy 2010; Brossard et al. 2013).

Tal dicotomia teórica demonstra que, assim como os próprios agentes, a influência exercida pelos investidores institucionais sobre as estratégias corporativas pode não ser homogênea. Esta heterogeneidade, no entanto, não é captada somente pela diferenciação dos mesmos por características gerais - como, por exemplo, se asset manager, fundo de pensão ou seguradora. Tal diferenciação, apesar de importante, não é suficiente, por não necessariamente explicitar a variedade de composições que abarcam tais grupos e a significativa variação intragrupos em termos de horizonte de investimento e sensibilidade aos eventos correntes (Bushee 2004; Chen et al. 2007; Ferreira e Matos 2008; Brossard et al. 2013; Çelik e Isaksson 2013; Katan e Mat Nor 2015; Crane et al 2016; Colot e Bauweraerts 2016).

Neste contexto, o objetivo deste trabalho é verificar quais investidores institucionais atuam no mercado de capitais brasileiro como acionistas de CNF de capital aberto, em particular, busca-se compreender o perfil do investimento empreendido por tais agentes. Em outras palavras, investigam-se quais as principais características e qual o grau de heterogeneidade no histórico de atuação dos investidores institucionais presentes na estrutura de propriedade e controle das CNF brasileiras, identificando em que aspectos tais agentes apresentam comportamentos semelhantes ou divergentes.

Para alcançar esse objetivo, a pesquisa recorre a métodos de classificação e agrupamento a partir de dados disponíveis entre 2011 e 2016. Os resultados do estudo identificam a presença de 346 investidores institucionais acionistas de 165 CNF brasileiras de capital aberto, atuantes no período acima citado. Com base em fatores formados pela posição nas empresas investidas, grau de diversificação, estabilidade do portfólio e influência marginal, tais investidores foram agrupados em quatro clusters, sendo observada forte heterogeneidade intragrupo. Em dois clusters, os resultados apontam para um perfil caracterizado pela miopia dos investimentos (denominados de curto-prazistas); por outro lado, outros dois clusters indicaram ter um perfil menos volátil (com perfil de investimento de mais longo prazo e conservador), existindo diferenças entre eles relativas ao grau de diversificação da carteira e à origem (se nacional ou não) e tipo (se estatal ou privado) de investidor. 
Como, em geral, as metodologias de agrupamento utilizadas pelas pesquisas sobre o tema se baseiam em classificações predefinidas, que não incorporam, por exemplo, uma série de variações em termos de perfil de investimento dos agentes, este estudo consiste em uma importante contribuição à literatura. Ao identificar, caracterizar e agrupar investidores institucionais nacionais e estrangeiros, públicos e privados, pertencentes ou não a um conglomerado financeiro, de acordo com o seu perfil de investimento, esta pesquisa torna possível incorporar o grau de heterogeneidade destes agentes em futuras pesquisas sobre, por exemplo, o ativismo de acionistas ou a qualidade, em termos de horizonte temporal, do capital provido por investidores institucionais às empresas. Neste sentido, torna-se possível explorar e distinguir o possível impacto dos diferentes perfis de investidores institucionais tanto sobre as decisões relativas à gestão estratégica das corporações, como também sobre o desempenho econômico-financeiro de tais empresas. Além disso, a heterogeneidade intragrupos é uma questão ainda pouco explorada no caso específico dos países emergentes. Para o Brasil, em particular, não foram encontradas pesquisas que diferenciem os investidores institucionais pela sua forma de atuação no mercado acionário.

\section{Revisão de literatura}

Segundo Çelik e Isaksson (2013), as possíveis diferenças no tipo de influência potencialmente exercida pelos investidores institucionais estão associadas a uma série de características que, juntas, formam o modelo de negócios de cada investidor. Tais fatores variam não só entre as diferentes classificações legais, mas também dentro de uma mesma classificação. Por essa razão, é relevante incorporar à análise os fatores que orientam a atuação dos investidores institucionais no mercado, diferenciando-os pelo seu perfil de investimento.

Devido ao caráter qualitativo e observacional da metodologia de avaliação do modelo de negócios proposta pelos autores, sua replicação é dificultada para grandes amostras. ${ }^{1}$ No entanto, tendo reconhecido que o efetivo

1 Çelik e Isaksson (2013) identificaram sete determinantes desagregados em 19 características que, em diferentes combinações, definiriam o modelo de negócios de cada investidor. Tais informações foram utilizadas na criação de uma taxonomia não exaustiva de identificação dos diferentes níveis de ativismo. As diferenças variam desde uma posição passiva, passando por escolhas tomadas a partir de 
entendimento das implicações da propriedade institucional requer que diferentes características destes investidores sejam consideradas, pesquisas recentes incorporaram o fato de tais agentes não formarem um grupo homogêneo.

Neste contexto, os investidores institucionais passaram a ser diferenciados, entre outros fatores, pelo país de origem, pelo fato de o capital ser privado ou estatal e/ou pela relação de negócios estabelecida junto à corporação. Este último aspecto é o principal fator de diferenciação incorporado pela maioria das pesquisas sobre o tema. A hipótese, inicialmente proposta por Brickley et al. (1998), é a de que investidores com o potencial de estabelecer vínculos comerciais com a companhia investida teriam menor independência, o que, por sua vez, comprometeria seu ativismo - no sentido de monitorar as decisões corporativas e demandar mudanças na gestão. Em outras palavras, os autores diferenciaram investidores "dependentes" e "independentes" pelo potencial de se sujeitarem à pressão exercida pela gestão devido às relações comerciais vigentes.

Os estudos sobre o tema têm classificado diferentes investidores em cada uma das duas categorias, assim como as designado por distintos nomes. Ferreira e Matos (2008), por exemplo, testaram a hipótese de que tanto as preferências dos investidores institucionais no que tange à alocação do seu portfólio quanto o impacto da sua participação como acionistas sofreria influência pelo fato de o investidor ser nacional ou estrangeiro, assim como dependente ou independente. Os autores avaliaram a atuação de investidores institucionais de 27 nacionalidades, acionistas de 11.224 empresas, localizadas em 48 países, no período 2000-2005. Os resultados obtidos indicaram que o padrão de disclosure nacional foi determinante da atração dos investidores institucionais. Além disso, destacaram-se como determinantes da alocação de capital por investidores estrangeiros o fato de a empresa pertencer ao índice Morgan Stanley Capital International (MSCI) e estar listada em bolsas norte-americanas. No que tange ao efeito do maior ativismo dos investidores institucionais, notou-se que a presença de instituições estrangeiras e independentes gerou valor.

critérios gerais e predefinidos, até a influência por retornos acima do benchmark ou práticas como o voto direto e a participação no conselho de administração. 
O trabalho de Colot e Bauweraerts (2016), por sua vez, investigou como a presença de diferentes tipos de investidores institucionais afetou a criação de valor em empresas francesas de capital aberto com controle familiar. Os autores diferenciaram investidores sensíveis e insensíveis à pressão de acordo com o grau de independência discutido anteriormente. Os resultados apontaram que investidores insensíveis à pressão levaram a um melhor desempenho, uma vez que possuíam o incentivo e a capacidade para contestar a família e influenciar a gestão.

Observa-se que a diferenciação dos investidores institucionais a partir dos laços estabelecidos junto à gestão é útil por explicitar um aspecto adicional às classificações gerais identificadas $a$ priori. No entanto, usualmente, parte-se de uma classificação predefinida, que não necessariamente explicita a potencial variação intragrupos. Assim sendo, desconsideram-se fatores - como o valor do investimento, a sensibilidade aos retornos correntes e a estabilidade da participação - que podem influenciar a postura dos investidores institucionais frente à gestão das empresas, alterando o sentido e o grau da sua influência sobre a estratégia corporativa.

Bushee $(1998,2001)$ foi pioneiro na análise da heterogeneidade dos investidores institucionais. ${ }^{2}$ Segundo o autor, diferentes fatores afetam a sensibilidade destes investidores ao desempenho das empresas no curto-prazo, tornando necessário questionar que tipo de investidor provê um capital com perfil de longo prazo. Duas características principais foram consideradas: estabilidade e tamanho da participação. Os investidores foram, então, classificados em três grupos: dedicados, quasi-indexers e transitórios. Enquanto o primeiro grupo foi formado por investidores com elevadas participações de caráter mais estável, o último agregou investidores que apresentaram elevado turnover do portfólio e detiveram pequenas participações nas companhias. O grupo dos quasi-indexers, apesar da estabilidade das participações, as possuía em reduzidos percentuais.

Observou-se que as chances de a gestão se comprometer com a geração de valor a longo prazo é consequência de sua própria postura em relação ao grau de disclosure da companhia. O disclosure em séries mais longas auxiliaria o monitoramento do desempenho segundo expectativas de longo prazo, atraindo investidores quasi-indexers. Tal mudança na estrutura de

2 Os trabalhos de Bushee foram a principal referência bibliográfica para a metodologia aplicada nesta pesquisa. O autor também recorre à análise fatorial e de cluster para classificação e agrupamento dos investidores institucionais. Bushee (2004) apresenta uma síntese da metodologia de classificação dos investidores institucionais utilizada pelo autor. 
propriedade, por sua vez, retroalimentaria a menor preocupação dos gestores com as métricas de curto prazo uma vez que seus principais investidores seriam caracterizados pela menor sensibilidade às mesmas.

Chen et al. (2007) também avaliaram a existência de uma relação entre o grau de monitoramento e não só o perfil do investimento (se de curto ou longo prazo), mas também o tamanho da participação e o nível de independência de cada investidor. Neste caso, bancos, seguradoras, endowments foundations e fundos de pensão privados foram denominados "cinzas" em virtude da menor independência. Já o perfil do investimento foi mensurado pelo período em que a posição foi mantida. A amostra do estudo foi composta por todas as fusões ocorridas nos Estados Unidos entre 1984 e 2001, totalizando 2.150 operações. Os resultados indicaram que instituições independentes e com grandes participações em uma empresa por pelo menos um ano têm maiores incentivos para coletar informações, optando por participar ativamente da gestão e obter como benefício privado retornos a longo prazo.

Katan e Mat Nor (2015), alinhados aos estudos anteriores, advertiram que os objetivos do investimento institucional não seriam uniformes, diferindo significativamente em termos do tamanho da participação, propósito, objetivo, bem como esforços de monitoramento da instituição. Os autores dividiram os investidores institucionais em dois grupos: dedicados e transitórios. O primeiro grupo foi formado pelos fundos de pensão e fundos públicos, já o segundo pelos demais investidores. A amostra foi composta por todas as empresas listadas no índice malasiano Kuala Lumpur Composite Index (KLCI) no período 2002-2006.

A hipótese dos autores era que investidores dedicados, devido ao tamanho e ao prazo da sua participação, seriam mais ativos no monitoramento das empresas, otimizando o seu desempenho. Investidores transitórios, por sua vez, devido à elevada rotatividade e diversificação da sua carteira, teriam um horizonte de investimento de curto prazo, vendendo suas participações sempre que a companhia frustrasse suas expectativas de retorno. Os resultados, no entanto, não corroboraram as hipóteses suscitadas. Enquanto a propriedade de investidores do tipo dedicado não influenciou o desempenho corporativo, a presença de investidores transitórios foi significativa e positivamente relacionada ao desempenho das companhias investidas. 
Brossard et al. (2013) também exploraram, entre outros fatores, o nível de independência do investidor, focando na sua influência sobre os esforços inovativos das companhias. Os autores consideraram diferentes dimensões para a caracterização dos investidores institucionais, diferenciando-os conforme: o nível de independência, a rotatividade de carteira, a nacionalidade e a concentração de propriedade. A análise com dados em painel das 325 empresas mais inovativas da Europa, no período 2002-2009, corroborou a hipótese de que investidores dependentes ou 'cinzas' são menos propensos a apoiar decisões mais arriscadas, como as relacionadas à inovação. Já as empresas europeias com os maiores níveis de investimento em Pesquisa e Desenvolvimento (P\&D) apresentaram uma estrutura de propriedade dominada por investidores independentes e, portanto, mais ativos em termos de governança corporativa.

O estudo de Kim et al. (2017) também avaliou a relação entre a heterogeneidade dos investidores institucionais e a inovação em corporações norte-americanas entre 1980 e 2004. Os resultados apontaram para uma influência positiva dos investidores com perfil de investimento de longo prazo, ou seja, corporações com a presença destes investidores institucionais apresentaram maior dinamismo inovativo (número e citações de patentes). Kim et al. (2018) investigaram o impacto da heterogeneidade dos investidores institucionais sobre as atividades de responsabilidade social corporativa (RSC), também no mercado norte-americano, no período 1995-2012. Os autores obtiveram evidências de que empresas com investidores institucionais com perfil ativo e de longo prazo em sua estrutura de propriedade mostraram um maior engajamento em atividades de RSC. Fu et al. (2019), ao explorarem esta mesma temática, obtiveram resultados similares. Ou seja, investidores institucionais com maior horizonte temporal de investimento influenciaram positivamente as atividades de RSC.

Crane et al. (2016) abordaram o papel dos investidores institucionais em mitigar problemas de agência, mediante a política de distribuição de dividendos. Os autores atentaram para a endogeneidade da relação analisada, uma vez que ao mesmo tempo em que tais investidores influenciariam a política de dividendos, no sentido de sua ampliação, seriam atraídos por empresas que distribuíssem maior percentual do fluxo de caixa aos acionistas. A primeira relação, foco da análise, seria justificada pelos investidores institucionais possuírem maior expertise e interesse na avaliação do desempenho financeiro das empresas, assim como da qualidade da gestão e da governança, reduzindo os custos de coordenação e melhorando 
o monitoramento. A amostra do estudo consistiu nas empresas listadas no mercado norte-americano e presentes nos índices Russell entre 1991 e 2006. Os resultados indicaram que tais agentes mitigaram os conflitos de agência via influência direta sobre o pagamento de maiores dividendos. Tal resultado foi válido para todos os tipos de investidores, inclusive aqueles que não são tradicionalmente considerados ativistas.

Os trabalhos explicitados acima avaliaram, de forma geral, a influência que os diferentes grupos de investidores institucionais possuem sobre as decisões corporativas, apontando para a importância de se levar em conta a heterogeneidade destes agentes nas análises. No entanto, parte das classificações não considera nem a variedade de composições que abarcam tais grupos, nem a significativa variação intragrupos em termos do perfil de investimento de cada investidor. Além disso, as pesquisas referenciadas não só focam majoritariamente na experiência dos países avançados, como também não consideram as diferentes formas de organização salientadas por Çelik e Isaksson (2013) - que incorporam instituições subsidiárias de grandes corporações ou conglomerados financeiros. Neste sentido, as próximas seções avançam nesta temática, explorando a heterogeneidade dos investidores institucionais no mercado brasileiro.

\section{Metodologia}

\subsection{Métodos de análise}

Este artigo tem por objetivo classificar e agrupar os investidores institucionais que figuram como acionistas de CNF brasileiras de capital aberto. Para tanto, são utilizadas duas técnicas. Em primeiro lugar, emprega-se a análise fatorial, tendo em vista compilar variáveis correlacionadas entre si em fatores que evidenciem características-chave não observáveis. Em segundo lugar, recorre-se à análise de clusters, na qual somam-se aos componentes definidos outras características próprias das observações transversais, visando o agrupamento de agentes semelhantes, sem desconsiderar a heterogeneidade entre eles.

A análise de componentes principais ou PCA (Principal Component Analysis) visa transformar as variáveis observadas, fortemente correlacio- 
nadas entre si, em um conjunto menor de novas variáveis que são combinações lineares das variáveis originais, não são correlacionadas entre si e explicam o máximo possível a variância nos dados. Mediante a PCA, explora-se a correlação entre as variáveis de caracterização dos investidores institucionais para então definir componentes sintéticos que, por abarcarem a dimensionalidade desconhecida das variáveis observáveis, facilitam a discriminação eficiente dos distintos padrões de comportamento destes agentes.

Operacionalmente, esta pesquisa utiliza o comando "principal", do pacote psych, do software $\mathrm{R}$, sendo tal comando baseado na matriz de correlação. Além da elevada correlação entre as variáveis amostrais, são utilizadas duas medidas para avaliar a adequação dos dados à técnica da análise fatorial: medida de adequação da amostra ou MSA (Measure of Sampling Adequacy) e teste de Kaiser-Meyer-Olkin (KMO). Uma vez confirmada a adequabilidade da amostra à técnica, obtêm-se, a partir da decomposição da matriz de correlação, os autovalores (eigenvalues). $\mathrm{O}$ autovalor $\kappa_{j}$ representa a variabilidade explicada pelo fator $F_{j}$, equivalente à soma dos quadrados das correlações entre o fator e as variáveis observáveis $\left(a_{i}\right)$ :

$$
\kappa_{j}=\sum_{i=1}^{n} a_{i j}^{2}
$$

Como a finalidade dos autovalores é definir um conjunto de vetores independentes, não correlacionados, que expliquem o máximo a variabilidade dos dados, maximiza-se a variabilidade explicada das $n$ variáveis observáveis $X$ por meio do Fator 1 . O Fator 2 é então definido sobre a variabilidade não explicada, de modo que, com a definição do $n$-ésimo fator, a variância acumulada explicada pelo último componente adicional seja de $100 \%$. Maximiza-se, assim, a variabilidade explicada por cada fator até que se obtenha $n$ fatores que expliquem toda a variabilidade dos dados.

Como as variáveis observáveis $X$ são inicialmente padronizadas de modo a terem média 0 e variância 1 , a variabilidade total das $n$ variáveis observáveis será necessariamente igual a $n$ :

$$
\sum_{i=1}^{n} \operatorname{Var}\left(X_{i}\right)=1+1+\ldots+1=n
$$


Já a porcentagem da variabilidade explicada pelo $j$-ésimo fator será dada por:

$$
\% \text { Variabilidade }_{j}=\frac{\Upsilon_{j}}{n} \cdot 100
$$

Enquanto a parcela da variabilidade total da $i$-ésima variável $X_{i}$ explicada pelos $n$ fatores comuns $F$ é denominada comunalidade $\left(h_{i}^{2}\right)$ e definida como:

$$
h_{i}^{2}=\sum_{j=1}^{n} a_{i j}^{2}
$$

Para ampliar o potencial de interpretação da relação entre os fatores e as variáveis observáveis $\left(a_{i}\right)$, sem alterar o poder explanatório dos primeiros, pode-se recorrer a uma transformação linear denominada rotação dos eixos coordenados (Johnson e Wichern 2013). Devido à possível ambiguidade na análise dos resultados obtidos pela rotação oblíqua, ${ }^{3}$ foram considerados os métodos de rotação ortogonal Varimax e Promax. Enquanto o método Varimax minimiza o número de variáveis que apresentam altas cargas em cada fator, o Promax desconsidera o pressuposto de independência entre os fatores, permitindo que os mesmos rotacionem livremente - o que simplifica sua interpretação (Hair et al. 2009).

Por meio do grau de dependência linear entre cada variável observável e cada um dos fatores comuns, denominado carga fatorial, são definidos os coeficientes lineares (scores fatoriais) que estimarão o valor previsto de cada fator em função das variáveis observáveis. Ou seja, a estrutura de ponderações resultante da análise fatorial será utilizada na construção de novas variáveis. Estas últimas, somadas a outros indicadores de cunho qualitativo, descreverão o comportamento dos investidores institucionais como acionistas das empresas brasileiras, tornando possível agrupá-los, via análise de clusters, segundo o seu modo de atuação e principais características.

Em relação à análise de cluster, diversas opções metodológicas se apresentam. O método utilizado nesta pesquisa é o PAM (partitioning around medoids), muito similar ao k-means, no sentido em que também se baseia

3 Apesar de a rotação oblíqua usualmente produzir modelos mais satisfatórios que a ortogonal, seus fatores são correlacionados, fazendo com que não se delimite uma medida única da importância de cada fator na explicação de uma determinada variável (Maia 2002). 
no princípio do agrupamento hierárquico aglomerativo, diferenciando-se apenas por definir os centros dos clusters como as próprias observações (medoides). Em síntese, $k$ observações aleatórias são escolhidas para tornarem-se os medoides, atribuindo-se cada observação da amostra ao seu medoide mais próximo (com base na matriz de distância de Gower ${ }^{4}$ ). A partir deste agrupamento, busca-se pela observação que produziria a menor distância média se fosse redefinida como o medoide. Caso esta seja encontrada, um novo medoide é definido, sendo o processo repetido até que nenhum medoide se altere.

Como aponta Maia (2006), amplia-se gradativamente o grau de generalização, movendo-se do cenário em que todas as observações são distintas entre si para aquele em que todas são consideradas semelhantes. A definição do número ideal de clusters, ou do grau de generalização adotado, é uma opção do pesquisador, podendo ser embasada na contribuição parcial de cada autovalor à variabilidade dos dados. No caso desta pesquisa, o critério são autovalores (eigenvalues) superiores a 1. Ademais, os resultados são analisados graficamente, comparando a capacidade explanatória dos autovalores obtidos a partir dos dados observados com os embasados em uma matriz de dados aleatórios do mesmo tamanho que a original. Rupturas acentuadas no gráfico sugerem o número apropriado de componentes a ser extraído.

Para verificação dos resultados obtidos pelo algoritmo de agrupamento, utiliza-se uma das principais medidas de validação interna, o Silhouette coefficient $(S)$. Esta última consiste em uma medida de quão similar uma observação é do seu próprio cluster, em comparação ao cluster mais próximo. Assim, o coeficiente estima tanto se uma observação foi bem agrupada quanto, e consequentemente, a distância média entre os clusters. Quanto mais alto o valor de $S$ (próximo a 1) melhor. Um $S$ pequeno (em torno de 0) significa que a observação se situa entre dois clusters, enquanto observações com um $S$ negativo provavelmente foram alocadas no cluster incorreto.

4 A matriz de distância de Gower utiliza uma métrica de distância específica para cada tipo de variável: distância de Manhattan no caso variáveis contínuas e coeficiente de Dice no caso das binárias. A primeira pode ser definida como a soma das diferenças entre $x$ e $y$ em cada dimensão. Já a segunda pode ser interpretada como uma medida da proporção de coocorrência. Ou seja, como o fato de o investidor A possuir determinada característica que o investidor B não possui tem o mesmo valor de o investidor B possuir determinada característica que A não possui, atribui-se maior importância ao fato de ambos possuírem simultaneamente uma determinada característica. 


\subsection{Amostra do estudo}

Partiu-se de uma amostra composta por todas as empresas brasileiras de capital aberto, emissoras de ações ordinárias, considerado o período 20112016. ${ }^{5}$ Foram então eliminadas as companhias pertencentes aos setores de finanças, seguros e fundos, resultando em uma amostra de 269 empresas brasileiras não financeiras de capital aberto.

Dados trimestrais do percentual de participação e número de ações dos investidores foram coletados no software Economática. As companhias são obrigadas a divulgar somente um formulário de referência anual, sendo os demais majoritariamente retificadores. Por este motivo, optou-se por manter o primeiro formulário mais completo em cada ano - nos casos em que a soma da participação dos acionistas diferiu de $100 \%$, verificou-se a divulgação completa mais próxima. Além disso, para garantir a análise dos investidores institucionais que possuem uma participação conjunta expressiva, filtrou-se aqueles acionistas com participação superior a 5\% na estrutura de controle. Outra motivação para tal filtro é o fato de as empresas no Brasil somente serem obrigadas a divulgar os acionistas com tal participação mínima.

Delimitou-se, assim, uma lista com um total de 1.043 acionistas. Estes últimos foram inicialmente classificados em oito categorias, ${ }^{6}$ sendo elas: i) asset managers: inclui fundos de investimento, capital investors, gestoras e administradoras de recursos, equity e investment partners, clubes de investimentos e corretora de valores; ${ }^{7}$ ii) fundos e institutos de pensão e seguridade social; iii) seguradoras; iv) pessoa física, famílias, holdings familiares e subscritas por pessoa física; iv) companhias não financeiras e empresas de consultoria empresarial; v) bancos e empresas financeiras; vi) governo; vi) outros: administradores e conselheiros, associação de funcionários, demais membros do acordo de acionistas, fundações, ONG's, entre outros.

5 O início em 2011 se deve às alterações nas normas de contabilidade brasileiras em resposta à iniciativa de padronizá-las conforme os padrões internacionais sugeridos pela International Accounting Standard Board (IASB), o chamado International Finance Report Standard (IFRS).

6 Os acionistas foram individualmente categorizados a partir da classificação CNAE (Cadastro Nacional de Atividade Econômica), disponibilizada pela Receita Federal, por meio da consulta ao CNPJ (Cadastro Nacional de Pessoa Jurídica) da entidade. Nos casos em que tais acionistas eram reconhecidamente pertencentes à outra categoria que não a delimitada pela referida classificação (possivelmente muito abrangente), foi mantida a categoria identificada pela busca on-line (baseada no site das próprias instituições e em informações divulgadas pela Comissão de Valores Mobiliários, B3 ou pelas companhias investidas, como, por exemplo, nos avisos de fato relevante).

7 Parte destes investidores poderia, também, negociar seguros e planos de previdência, apesar de não ter sido caracterizada como tal por esta não ser sua atividade final e/ou exclusiva. 
Dos 1.043 acionistas, 364 eram institucionais (asset managers, fundos e institutos de pensão e seguridade social e seguradoras). Estes últimos foram então classificados em três categorias adicionais (variáveis categóricas): a) categoria A: nacional ou internacional; b) categoria B: público ou privado; c) categoria C: dependente ou independente. Nos casos em que o fundo e/ou subsidiária pertencia a um grupo internacional, o acionista foi considerado estrangeiro mesmo que com registro no Brasil. Analogamente, se pertencia a um indivíduo ou grupo brasileiro foi considerado nacional mesmo que com registro em outro país. Além disso, foram definidos como asset managers dependentes os que eram subsidiárias de um grupo ou conglomerado financeiro. Nos casos dos fundos de pensão, foram considerados independentes aqueles relativos às empresas privadas. ${ }^{8}$ Fundos de investimento inteiramente subscritos por outro investidor institucional tiveram sua classificação baseada neste último, apesar de a definição como independente considerar o gestor da carteira e não o seu administrador.

Conforme a Tabela 1, os fundos de pensão se mostraram como a categoria com maior porcentagem de investidores nacionais e estatais. Por outro lado, asset managers privados e independentes, ou seja, que não são parte de conglomerados financeiros, foram a maioria neste grupo, sendo equilibrado o número de investidores nacionais e internacionais. Entre as seguradoras, categoria com o menor número de investidores, também a metade se apresentou como nacional, enquanto um quarto foi considerado independente. Para a amostra como um todo, observa-se um equilíbrio entre investidores nacionais e estrangeiros. Por outro lado, investidores privados independentes foram maioria entre os acionistas das empresas no período.

8 Lazzarini (2011) salienta a importância dos fundos de pensão de empresas públicas na estrutura de propriedade e controle das companhias brasileiras, enfatizando o ganho de poder político e econômico destes grupos não só no âmbito corporativo, mas na economia nacional - principalmente a partir dos anos 1990 devido às privatizações e à formação de consórcios. A organização de leilões estimulava a formação de consórcios destinados a exercer o controle compartilhado das companhias privatizadas, nas quais, investidores institucionais, majoritariamente fundos de pensão de empresa públicas nacionais, detinham participações expressivas (Siffert filho 1998; Black et al. 2008). 
Tabela 1 - Porcentagem de investidores institucionais por classificação e categoria

\begin{tabular}{lcccc}
\hline & Asset Manager & Fundo de pensão & Seguradora & Total \\
\hline$n$ & 323 & 19 & 4 & 346 \\
\hline \multirow{4}{*}{ Nacional (\%) } & \multicolumn{4}{c}{ Categoria A (nacional ou internacional) } \\
\cline { 2 - 5 } Internacional (\%) & 53,87 & 73,68 & 50,00 & 54,91 \\
\hline & 46,13 & 26,32 & 50,00 & 45,09 \\
\hline \multirow{4}{*}{ Estatal (\%) } & 3,1 & Categoria B (público ou privado) \\
Privado (\%) & 96,9 & 47,37 & 0,00 & 5,49 \\
\hline & \multicolumn{4}{c}{ Categoria C (dependente ou independente) } \\
Independente (\%) & 70,9 & 36,84 & 25,00 & 64,51 \\
Dependente (\%) & 29,1 & 63,16 & 75,00 & 31,5 \\
\hline
\end{tabular}

Fonte: elaboração própria a partir de dados da pesquisa.

\subsection{Variáveis explanatórias}

Dentre as 269 empresas analisadas, 165 delas continham investidores institucionais entre os seus principais acionistas (com participação superior a 5\%). Para tais investidores, foram definidas 17 variáveis com a finalidade de captar quatro fatores não observáveis: posição nas empresas investidas, grau de diversificação, estabilidade do portfólio e influência marginal. Tais fatores foram definidos ex-ante e tiveram base na revisão da literatura. As variáveis utilizadas para delimitação dos fatores comuns são apresentadas e, quando necessário, explicadas abaixo:

1. Número de empresas investidas $(N E)$;

2. Número de setores investidos (NS);

3. Valor do investimento (VALOR): soma do valor resultante da multiplicação entre o preço e o número das ações detidas pelo investidor em cada empresa no respectivo ano;

4. Participação percentual média do investidor nas empresas investidas (PM);

5. Percentual de grandes blocos (acima de 10\%) no portfólio (PGB): por exemplo, caso o investidor tivesse participação superior a $10 \%$ em cinco empresas de um total de 10 empresas investidas, a variável assumiu o valor de $50 \%$; 
6. Porcentagem do portfólio em que a posição se alterou anualmente (VP): por exemplo, caso o investidor tenha alterado sua posição em cinco de 10 empresas investidas entre um ano e outro, a variável assumiu o valor de 50\%;

7. Número de vezes em que o acionista passou ou deixou de constar na base de dados: foram criadas duas variáveis, uma para contabilizar a entrada e outra para registrar a saída do investidor do mercado acionário brasileiro $(D E, D S)$;

8. Porcentagem de empresas em que a magnitude da variação da posição foi baixa (entre 1\% e 6\%) (VPB): por exemplo, caso o investidor tenha alterado sua posição nesta faixa de magnitude em uma de 10 empresas investidas, entre um ano e outro, a variável assumiu o valor de 10\%. Não havendo informações sobre a participação anterior à entrada, nem sobre a posterior saída da companhia, definiu-se que tais posições correspondiam a $4 \%$ do capital próprio. Isto porque, como a declaração é obrigatória somente para participações superiores a 5\%, há a possibilidade de investidores aparecerem em anos descontínuos por oscilarem em patamares próximos, porém inferiores a 5\% (e não por deixarem de ou passarem a ser acionistas). Caso este ajuste não fosse feito, variações de uma posição inferior a $5 \%$ (por exemplo, igual a 4\%) para uma marginalmente superior a 5\% (por exemplo, igual a 6\%) não seriam consideradas como mudança na posição, mas como 'entrada' no mercado. Uma importante vantagem deste indicador se refere à possibilidade de interpretação de pequenas mudanças de posição como oscilações em torno de um patamar mínimo de influência; ${ }^{9}$

9. Número de vezes em que houve variação percentual da posição nas empresas $(N V P)$;

10. Número de vezes em que houve variação percentual da posição nas empresas em cada patamar de variação (baixo, médio e alto), segundo magnitude da variação (1-10\%, 10-50\% ou acima de 50\%) (NVPB, NVPM, NVPA);

11. Número de empresas em que o investidor não alterou a quantidade de ações detidas em relação ao total de empresas investidas no intervalo de dois anos (PM1): este indicador mensurou o nível de estabilidade pela porcentagem do portfólio que não se alterou ao longo de dois anos, incorporando em seu denominador todas as empresas investidas no período;

9 O intervalo entre $1 \%$ e $6 \%$ se justifica pela participação mínima inicial ou final ter sido definida como $4 \%$, enquanto a participação em grandes blocos foi definida como $10 \%$. Ou seja, foca-se nas variações na posição cujo resultado seja inferior à porcentagem definida como em grandes blocos. 
12. Número de empresas em que o investidor não alterou a quantidade de ações detidas por dois anos em relação ao total de empresas investidas no início do intervalo (PM2): este indicador não abarcou investimentos em novas empresas. Por exemplo, caso o investidor fosse acionista de 10 empresas no ano 1 e passasse a investir em outras 10 empresas no decorrer do período, mantendo-se estável em cinco empresas ao longo de dois anos, o indicador PM1 assumiria o valor de 25\% (5/20), enquanto o indicador PM2 seria de 50\% (5/10);

13. Porcentagem do portfólio em que o acionista passou ou deixou de ter $5 \%$ de participação (GI e PI, respectivamente): tais variáveis visaram captar o ganho ou a perda de influência dos investidores institucionais entre as companhias brasileiras. Por exemplo, caso o investidor fosse acionista de oito empresas no início do período, alcançasse uma participação superior a $5 \%$ em duas empresas e reduzisse sua participação - para um percentual inferior a 5\% - em uma empresa no decorrer do ano, o indicador de ganho de influência assumiria um valor de $25 \%$, enquanto o indicar de perda de influência seria de $12,50 \%$.

Como se optou por considerar todo o intervalo na análise fatorial, cada investidor institucional deteve somente uma observação para cada variável, equivalente à média anual no intervalo entre 2011 e 2016 (com exceção das variáveis de contagem cujo valor corresponde à soma no período). Tal opção metodológica implica não haver mudança de cluster entre os anos. ${ }^{10}$

A Tabela 2 mostra as estatísticas descritivas da amostra. A grande maioria dos investidores da amostra foi classificada como asset managers (323 investidores), seguidos por fundos de pensão (19) e seguradoras (4).

Os fundos de pensão investiram, em média, em um número maior de empresas $(N E)$ e setores (NS), com maior porcentagem da carteira mantida em grandes blocos $(P B G)$. A participação média $(P M)$, por sua vez, não difere expressivamente entre os diferentes grupos de investidores, porém os dados apontam para uma maior estabilidade do portfólio dos fundos de pensão - dada a maior porcentagem média do portfólio mantida continuamente por dois anos (PM2) e a baixa variação na posição $(V P)$, além

\footnotetext{
${ }^{10}$ Parte dos fatores não pôde ser calculada para todos os investidores devido à falta de informações suficientes no período. Por isso, a análise de cluster se baseia em 346 investidores institucionais.
} 
de apresentarem um menor número de entradas $(D E)$ e saídas $(D S)$ como acionista das companhias.

As seguradoras, por sua vez, apresentaram maiores médias de participação $(P M)$, apesar da diferença em relação aos demais grupos não ser alta. Por outro lado, o valor investido (VALOR) e a participação em grandes blocos $(P B G)$ tiveram os menores valores entre as classificações consideradas. Em complemento, evidencia-se, em uma elevada porcentagem de empresas que compõem o portfólio das seguradoras, uma baixa magnitude da variação na posição $(V P)$ - mesma característica observada nos fundos de pensão, além do reduzido número de vezes em que houve variação percentual da posição nas empresas (NVP), o menor entre as classificações.

Em relação aos asset managers, estes tiveram maiores montantes investidos (VALOR), apresentando também maiores mudanças em suas posições em relação aos demais agentes, como mostram as variáveis $V P, N V P, G I$ e $P I$. A elevada variação percentual média no portfólio $(V P)$ e o maior número de vezes que houve variação percentual da posição nas companhias (NVP), por exemplo, sugerem elevado turnover no portfólio destes agentes ao que se associa a esperada volatilidade nas posições destes investidores juntos às empresas investidas.

Em linhas gerais, o número médio de empresas (NE) e setores (NS) investidos foi baixo, existindo alta participação média nas companhias $(P M)$. A porcentagem do portfólio mantida em grandes blocos $(P B G)$ também se demonstrou bastante elevada, cerca de $40 \%$. Como esperado, a dinâmica de mudança nas posições seguiu o padrão observado para os asset managers - maioria na amostra. A porcentagem do portfólio em que houve variação percentual na posição $(V P)$ foi elevada, principalmente em percentuais baixos $(V P B)$. Por outro lado, o número de entradas e saídas do mercado acionário brasileiro ( $D E$ e $D S)$ foi relativamente baixo, assim como o número médio de vezes em que houve variação percentual na posição, seja média ou alta. Ao contrário, a porcentagem média do portfólio em que houve ganho ou perda de influência foi alta. No que tange à estabilidade, a porcentagem média do portfólio da amostra mantida continuamente por dois anos foi relativamente baixa. 


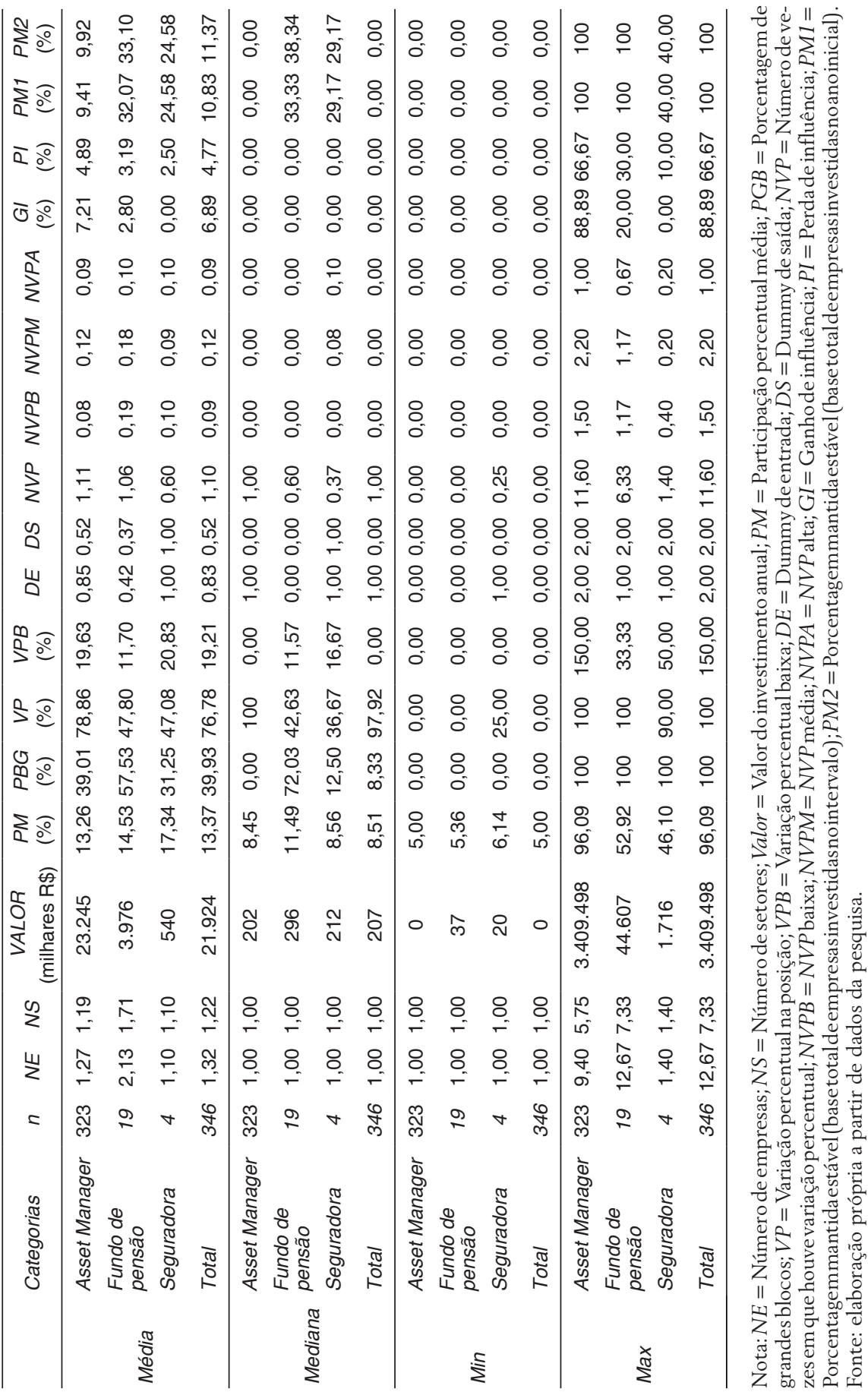




\section{Resultados}

\subsection{Análise fatorial}

O Anexo 1 apresenta a correlação entre as variáveis definidas para caracterização do perfil de investimento dos investidores institucionais. O número de empresas investidas (NE) foi altamente correlacionado com o número de setores (NS) e de vezes em que o investidor alterou sua participação percentual (NVP). Espera-se, portanto, que investidores com participação acionária em poucas empresas, mais especializados, alterem menos a sua posição. Adicionalmente, a participação acionária média dos investidores institucionais nas empresas da amostra $(P M)$ teve uma correlação expressiva com a participação em grandes blocos (PGB), ou seja, participações acionárias superiores a $10 \%$. A dummy de entrada no mercado $(D E)$ foi negativamente correlacionada com as variáveis de estabilidade (PM1, PM2) e positivamente correlacionada com a de variação percentual (VP). A variável que capta pequenas variações percentuais na posição $(V P B)$, ou seja, entre $1 \%$ e $6 \%$, demonstrou-se muito correlacionada às variáveis de ganho e perda de influência (GI e PI). Esta relação era também esperada uma vez que tais indicadores são comuns aos investidores que oscilam em torno da posição mínima necessária para exercer alguma influência.

A variável, que capta especificamente pequenas variações percentuais na posição $(V P B)$, ou seja, entre $1 \%$ e $6 \%$, demonstra-se muito correlacionada às variáveis de ganho e perda de influência (GI e PI, respectivamente). Esta relação era também esperada uma vez que tais indicadores são comuns aos investidores que oscilam sua posição em torno da mínima necessária para o exercício de alguma influência.

Os diferentes patamares de magnitude da variação percentual na posição $(N V P B, N V P M$ e $N V P A)$ não foram muito correlacionados entre si, indicando a existência de um padrão de comportamento - investidores caracterizados por variações percentuais de pequena magnitude em um grande número de empresas não seriam inclinados a grandes variações, e vice-versa. Por outro lado, as variáveis de ganho e perda de influência (GI e PI) se apresentaram muito correlacionadas entre si. Esta última correlação parece demonstrar que os investidores que ganham influência - pelo critério estabelecido - são os mesmos que perdem. Isto porque variam sua posição em torno do patamar de 5\% em grande parte do seu portfólio. 
As estatísticas de adequação MSA são apresentadas no Anexo 2. Todas as variáveis tiveram adequação superior a 0,6 , considerada adequada. A mesma conclusão foi obtida pela estatística KMO (Hair et al. 2009; Figueiredo Filho e Silva Júnior 2010). ${ }^{11}$ Confirmada a adequação dos dados à técnica da análise fatorial, recorreu-se à análise gráfica para definir o número de fatores a ser considerado pelo método dos componentes principais. A ruptura presente na Figura 1 indica a definição de quatro componentes como a mais adequada.

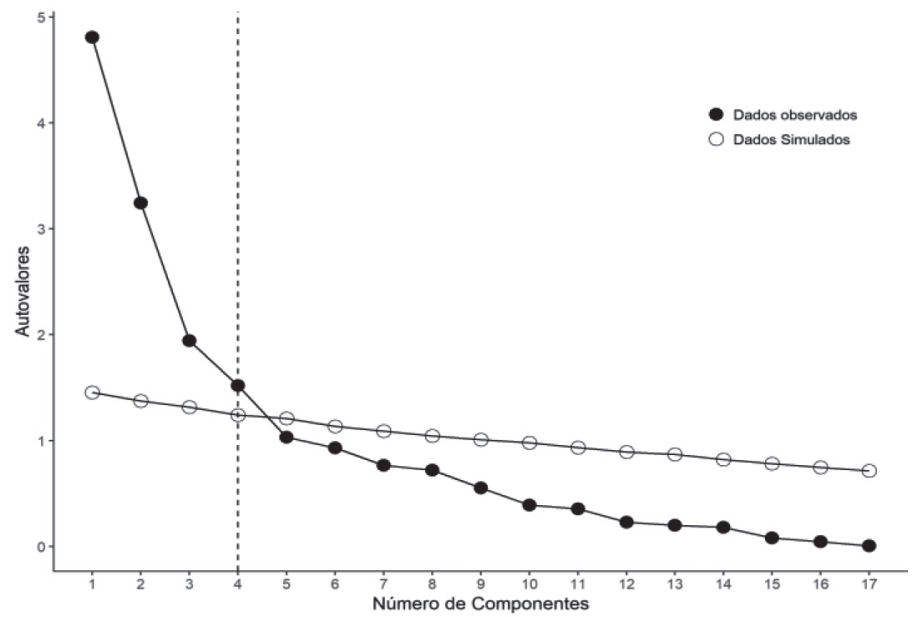

Figura 1 - Variância explicada pelos componentes principais

Fonte: elaboração própria a partir dos resultados da análise fatorial.

Os autovalores (eigenvalues) são apresentados na Tabela 3. O critério de Kaiser sugere utilizar os fatores com autovalores iguais ou superiores a uma unidade. Conforme primeira linha da tabela, os quatro componentes apresentaram autovalor superior a 1 . Além disso, o terceiro (quarto) componente principal respondeu por cerca de 59\% (68\%) da variabilidade total das 17 variáveis utilizadas (var acumulada).

${ }^{11}$ Todas as variáveis têm adequação superior a 0,6 , considerada adequada, sendo que a maioria possui adequação superior a 0,7 . Seis variáveis têm adequação meritória (superior a 0,8 ), sendo uma delas excelente (superior a 0,9). A adequação amostral, obtida pela estatística KMO, é também adequada, sendo igual a 0,762 (Hair et al. 2009; Figueiredo Filho e Silva Júnior 2010). 
Tabela 3 - Autovalores, peso relativo de cada componente na variância total e variância acumulada explicada por cada componente adicional

\begin{tabular}{lcccc}
\hline & PC1 & PC2 & PC3 & PC4 \\
\hline Autovalores & 4,8110 & 3,2450 & 1,9450 & 1,5180 \\
Var proporcional & 0,2830 & 0,1910 & 0,1140 & 0,0890 \\
Var acumulada & 0,2830 & 0,4740 & 0,5880 & 0,6780 \\
\hline
\end{tabular}

Fonte: elaboração própria a partir dos resultados da análise fatorial.

A análise fatorial pelo método PCA foi, portanto, baseada em quatro componentes, com cargas fatoriais dadas pela Tabela 4. Tais cargas (factors) são as correlações entre as variáveis observadas e os fatores, sendo que as cargas fatoriais relevantes são aquelas com valores superiores a 0,5 (células hachuradas).

Tabela 4 - Cargas fatoriais de cada componente para cada variável da pesquisa

\begin{tabular}{|c|c|c|c|c|}
\hline Variável & $\mathrm{PC} 1$ & PC2 & PC3 & PC4 \\
\hline$N E$ & 0,825 & 0,25 & 0,239 & $-0,292$ \\
\hline NS & 0,828 & 0,246 & 0,229 & $-0,280$ \\
\hline VALOR & & 0,150 & 0,157 & 0,257 \\
\hline$P M$ & $-0,128$ & 0,309 & 0,458 & 0,592 \\
\hline$P G B$ & & 0,368 & 0,502 & 0,557 \\
\hline$V P$ & 0,227 & $-0,859$ & 0,221 & \\
\hline$V P B$ & 0,658 & & $-0,517$ & 0,360 \\
\hline$D E$ & $-0,246$ & $-0,640$ & & $-0,127$ \\
\hline DS & $-0,167$ & $-0,276$ & $-0,224$ & $-0,227$ \\
\hline$N V P$ & 0,912 & & 0,143 & $-0,144$ \\
\hline$N V P B$ & 0,617 & 0,159 & 0,243 & $-0,259$ \\
\hline NVPM & 0,658 & 0,136 & 0,302 & \\
\hline$N V P A$ & 0,495 & 0,112 & 0,23 & 0,244 \\
\hline GI & 0,64 & & $-0,555$ & 0,358 \\
\hline PI & 0,661 & & $-0,559$ & 0,292 \\
\hline PM1 & $-0,248$ & 0,885 & $-0,250$ & $-0,162$ \\
\hline PM2 & $-0,216$ & 0,889 & $-0,265$ & $-0,163$ \\
\hline
\end{tabular}

Nota: $N E=$ Número de empresas; $N S=$ Número de setores; Valor $=$ Valor do investimento anual; $P M$ $=$ Participação percentual média; $P G B=$ Porcentagem de grandes blocos; $V P=$ Variação percentual na posição; $V P B=$ Variação percentual baixa; $D E=$ Dummy de entrada; $D S=$ Dummy de saída; $N V P=$ Número de vezes em que houve variação percentual; $N V P B=N V P$ baixa; $N V P M=N V P$ média; $N V P A$ $=N V P$ alta; $G I=$ Ganho de influência; $P I=$ Perda de influência; $P M 1=$ Porcentagem mantida estável (base total de empresas investidas no intervalo); PM2 = Porcentagem mantida estável (base total de empresas investidas no ano inicial).

Fonte: elaboração própria a partir dos resultados da análise fatorial. 
Obtidas as cargas fatoriais, realizou-se a estimação das comunalidades e das especificidades (Anexo 3). A maioria dos valores de comunalidade foi superior a 0,5. Ou seja, mais da metade da variância das variáveis foi captada pelos componentes considerados, indicando um bom ajuste da análise. Em mais de 50\% das variáveis, a variância captada pelos componentes superou $80 \%$, indicando alto poder de explicação destas variáveis pelo fator. As variáveis $V A L O R, D S$ e NVPA tiveram elevada especificidade, ou seja, houve uma proporção destas variáveis não compartilhada com as demais, fazendo com que mais de metade da sua variância não tenha sido explicada pelos fatores, reduzindo a relevância das mesmas na análise fatorial.

Na sequência, procedeu-se à rotação tanto pelo método Varimax quanto pelo método Promax. Ambos os métodos tiveram resultados semelhantes de modo que a opção pela apresentação e interpretação dos resultados obtidos pelo método Promax foi devido a diferenças marginais e a uma limitação de espaço (Tabela 5).

Tabela 5 - Resultados da PCA com rotação pelo método Promax

\begin{tabular}{|c|c|c|c|c|}
\hline Variáveis & $\mathrm{PC} 1$ & $\mathrm{PC} 2$ & PC3 & PC4 \\
\hline$N E$ & 0,982 & & & \\
\hline$N S$ & 0,971 & & & \\
\hline VALOR & & & & 0,344 \\
\hline$P M$ & $-0,187$ & & & 0,844 \\
\hline$P G B$ & $-0,102$ & & $-0,100$ & 0,852 \\
\hline$V P$ & & $-0,915$ & & \\
\hline$V P B$ & & & 0,920 & \\
\hline$D E$ & $-0,197$ & $-0,528$ & $-0,217$ & $-0,210$ \\
\hline$D S$ & $-0,147$ & & & $-0,380$ \\
\hline$N V P$ & 0,825 & $-0,235$ & 0,160 & $-0,105$ \\
\hline NVPB & 0,789 & & $-0,125$ & \\
\hline NVPM & 0,729 & & & 0,100 \\
\hline$N V P A$ & 0,346 & $-0,139$ & 0,165 & 0,343 \\
\hline GI & & & 0,944 & \\
\hline$P I$ & & & 0,913 & $-0,104$ \\
\hline PM1 & & 0,973 & & \\
\hline PM2 & & 0,978 & & \\
\hline SS loadings & 3,976 & 3,123 & 2,712 & 1,926 \\
\hline Proportion Var & 0,234 & 0,184 & 0,160 & 0,113 \\
\hline Cumulative Var & 0,234 & 0,418 & 0,577 & 0,690 \\
\hline
\end{tabular}

Nota: $N E=$ Número de empresas; $N S=$ Número de setores; Valor $=$ Valor do investimento anual; $P M$ $=$ Participação percentual média; $P G B=$ Porcentagem de grandes blocos; $V P=$ Variação percentual na posição; $V P B=$ Variação percentual baixa; $D E=$ Dummy de entrada; $D S=$ Dummy de saída; $N V P=$ Número de vezes em que houve variação percentual; $N V P B=N V P$ baixa; $N V P M=N V P$ média; $N V P A$ $=N V P$ alta; $G I=$ Ganho de influência; $P I=$ Perda de influência; $P M 1=$ Porcentagem mantida estável (base total de empresas investidas no intervalo); PM2 = Porcentagem mantida estável (base total de empresas investidas no ano inicial).

Fonte: elaboração própria a partir dos resultados da análise fatorial. 
Não há um processo objetivo para interpretação dos fatores. Em geral, busca-se analisar quais aspectos não observáveis são captados por cada componente a partir da importância do mesmo em predizer cada variável observável, nomeando-o de acordo com tal interpretação (Maia 2002, 2006). Para facilitar a análise dos resultados, foram consideradas as variáveis com correlação superior a 50\% com um dos quatro componentes principais selecionados (células hachuradas).

Observa-se que os indicadores referentes ao número de empresas (NE) e setores (NS) investidos, assim como aqueles relativos ao número de vezes em que os investidores variam sua posição ( $N V P, N V P B, N V P M, N V P A)$, particularmente em magnitudes percentuais baixas e médias (NVPB, NVPM), apresentaram relações positivas com o primeiro fator (PC1). Deste modo, infere-se que este componente capte o grau de diversificação dos investidores institucionais.

A análise dos coeficientes de correlação indicou que o fator 2 (PC2) esteve mais associado à estabilidade relativa da posição dos investidores institucionais como acionistas, sendo positivamente relacionado às variáveis de estabilidade na estrutura de propriedade, "PM1" e "PM2" e, em contrapartida, negativamente relacionado à variável de variação percentual na posição, "VP". Já o terceiro fator (PC3) esteve altamente correlacionado às variáveis de ganho $(G I)$ ou perda de influência $(P I)$, ou seja, às oscilações em torno do patamar de $5 \%$ de participação. Este último fator demonstrou-se também positivamente relacionado com o indicador de pequenas variações percentuais $(V P B)$. Deduz-se, portanto, que a dimensão captada pelo segundo componente principal (PC2) seja relativa à estabilidade das posições, enquanto o terceiro (PC3) capta a oscilação da posição em torno da definida como a mínima necessária para influenciar a gestão, denominada influência marginal e altamente associada à volatilidade.

Finalmente, o quarto fator $(P C 4)$ foi alta e positivamente relacionado às variáveis de participação média $(P M)$ e participação de grandes blocos $(P G B)$. A variável do valor do investimento (VALOR) e as dummies de entrada e saída ( $D E$ e $D S)$ também apresentaram relação expressiva, ainda que mais fracas, sendo as duas últimas negativamente relacionadas ao fator em questão. Assim, presume-se que o componente quatro (PC4) represente a dimensão implícita da posição (em grandes blocos) dos investidores nas empresas brasileiras. 


\subsection{Análise de cluster}

Obtidos os autovalores e as cargas fatoriais, foram determinados os coeficientes lineares (scores fatoriais) que servem de base para a estimação do valor previsto de cada componente principal em função das variáveis observadas. Aos quatro componentes obtidos a partir da estrutura de ponderações resultante da análise fatorial somaram-se variáveis binárias de cunho qualitativo com o objetivo de, por meio da análise de clusters, agrupar os investidores institucionais segundo suas principais características e perfil de investimento.

Como mencionado anteriormente, foram consideradas quatro características principais dos investidores institucionais: i) asset managers, fundos de pensão ou seguradoras; ii) nacionais ou internacionais; iii) públicos ou privados; e iv) dependentes ou independentes. A Tabela 6 resume as estatísticas descritivas dos clusters definidos.

Tabela 6 - Estatísticas descritas dos clusters

\begin{tabular}{|c|c|c|c|c|c|}
\hline & & Cluster 1 & Cluster 2 & Cluster 3 & Cluster 4 \\
\hline \multirow{9}{*}{ 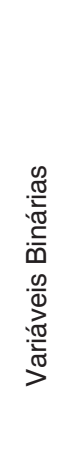 } & Asset Manager & 48 & 101 & 128 & 46 \\
\hline & Fundo de pensão & 3 & 2 & 5 & 9 \\
\hline & Seguradora & 1 & 1 & 0 & 2 \\
\hline & Nacional & 0 & 0 & 133 & 57 \\
\hline & Internacional & 52 & 104 & 0 & 0 \\
\hline & Estatal & 7 & 0 & 0 & 12 \\
\hline & Privado & 45 & 104 & 133 & 45 \\
\hline & Independente & 0 & 104 & 133 & 0 \\
\hline & Dependente & 52 & 0 & 0 & 57 \\
\hline \multirow{4}{*}{ 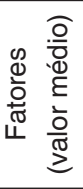 } & Diversificação & 0,13 & $-0,04$ & $-0,06$ & 0,22 \\
\hline & Estabilidade & $-0,01$ & $-0,06$ & $-0,05$ & 0,22 \\
\hline & Influência marginal & 0,30 & 0,17 & $-0,12$ & $-0,16$ \\
\hline & Posição & $-0,18$ & $-0,02$ & 0,06 & 0,26 \\
\hline \multirow{4}{*}{ 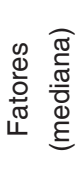 } & Diversificação & $-0,25$ & $-0,30$ & $-0,33$ & $-0,18$ \\
\hline & Estabilidade & $-0,39$ & $-0,54$ & $-0,54$ & $-0,37$ \\
\hline & Influência marginal & $-0,38$ & $-0,39$ & $-0,51$ & $-0,33$ \\
\hline & Posição & $-0,53$ & $-0,44$ & $-0,14$ & 0,11 \\
\hline
\end{tabular}

Fonte: elaboração própria a partir dos resultados da análise de cluster. 
Em linhas gerais, os Clusters 1 e 4 se caracterizaram por uma maior representatividade de investidores estatais, sendo todos dependentes, ou seja, geridos pelo governo ou subsidiárias de um grupo ou conglomerado financeiro. Em ambos os casos, evidenciou-se ainda uma maior diversificação. Porém, o Cluster 1, composto por fundos internacionais, foi caracterizado por uma menor estabilidade e maior influência marginal, ${ }^{12}$ além de reduzidas posições relativamente aos outros três grupos. Este grupo de investidores se apresenta mais aderente ao que Bushee $(1998,2001)$ apontou como agentes "transitórios", marcado por pequenas posições nas empresas com alto turnover do portfólio. Alternativamente, poderiam ser também denominados de "impacientes" dada a pouca estabilidade das posições, conforme Brossard et al. (2013) e Chen et al. (2007).

Já os investidores do Cluster 4, que engloba os fundos de pensão de empresas públicas nacionais, mostraram-se mais estáveis e assumiram maiores posições, além de, considerada a média, não oscilarem em torno do mínimo necessário para exercício de influência. Nota-se ainda que os investidores aí agrupados são todos nacionais e dependentes. Este grupo está mais próximo ao perfil denominado de "pacientes", segundo Brossard et al. (2013) e Chen et al. (2007) ou ainda "dedicados", conforme Bushee (1998, 2001), em que são constatadas elevadas participações dos agentes em questão nas companhias, sendo as posições estáveis.

Por outro lado, os Clusters 2 e 3 foram bastante semelhantes no que tange à sua composição, sendo ambos formados por investidores institucionais privados e independentes. Nesse caso, caracterizaram-se por posições intermediárias relativamente aos Clusters 1 e 4 e pela menor estabilidade e diversificação, também em relação aos clusters anteriormente analisados. As diferenças se concentraram nas posições assumidas e na influência marginal de investidores nacionais e internacionais. Enquanto os investidores internacionais (Cluster 2) pareceram oscilar em torno do patamar mínimo para exercício de influência, assumindo posições intermediárias, mas relativamente menores, os nacionais (Cluster 3 ) tiveram posições intermediárias (comparativamente aos demais clusters), mas não oscilaram em torno dos $5 \%$ de participação. ${ }^{13}$

12 Como explicitado na seção anterior, o fator influência marginal caracteriza investidores cuja participação acionária oscila em torno de 5\% - considerada a mínima necessária para exercício de alguma influência sobre a gestão. Vale notar que, considerada a mediana, não há uma diferença expressiva deste fator entre os clusters. As diferenças entre a média e a mediana derivam não só dos valores máximos, mas também dos observados no terceiro quartil, caracterizando os Clusters 1 e 2 como distribuições assimétricas, não tendo sido observada a presença de outliers.

${ }^{13}$ Quando considerada a mediana, e não o valor médio, tal diferença se mantém, apesar de ambos os clusters apresentarem valores negativos para tal fator. 
Os resultados identificaram quatro perfis distintos de investidor institucional. O Cluster 1 reuniu investidores diversificados, menos estáveis e com uma maior influência marginal associada a posições relativamente menores. Agruparam-se neste cluster os investidores, majoritariamente asset managers, aos quais usualmente se atribui maior volatilidade e, assim, potencial de influência sobre a miopia das estratégias corporativas - no sentido de demandar retornos no curto prazo em detrimento de políticas com horizonte temporal mais longo (Bushee 2004; Brossard et al. 2013). Já o Cluster 2 foi composto por investidores cujo modo de atuação foi também caracterizado por uma maior influência marginal e menor estabilidade. As diferenças em relação ao Cluster 1, além de este último ser composto por investidores privados e independentes, residiram na menor diversificação e nas posições relativamente maiores. Ou seja, os investidores do Cluster 2, que seriam potencialmente agrupados junto aos do Cluster 1 em trabalhos que não considerassem a heterogeneidade intragrupo, demonstraram-se mais especializados e assumiram posições menos líquidas que as assumidas pelos agentes agrupados no primeiro cluster.

Os investidores concentrados no Cluster 3, além de nacionais, privados e independentes, mostraram reduzida influência marginal. $O$ fato de serem nacionais, somado à menor oscilação em torno da posição mínima necessária para exercício de alguma influência, caracterizou um modo de atuação e potencial de ativismo distinto. Espera-se que tais investidores, apesar da limitada estabilidade, tenham um perfil menos volátil - associado a menor influência marginal, às maiores posições e, principalmente, à maior especialização. Tal perfil potencialmente repercutiria em um maior interesse em exercer influência sobre as empresas das quais são acionistas.

Por fim, o modo de atuação dos investidores reunidos no Cluster 4 se caracterizou pela maior diversificação, maior estabilidade, maiores posições e menor influência marginal entre todos os clusters delimitados - considerados os valores médios. Ou seja, tais investidores institucionais possuem características únicas que os distinguem como mais conservadores e, portanto, usualmente associados a uma maior capacidade de exercer influência sobre as companhias nas quais investem, tendo uma potencial visão de mais longo prazo (Chen et al. 2007; Ferreira e Matos 2008; Bebchuk et al. 2015; Crane et al. 2016). 
O Quadro 2 sumariza a heterogeneidade dos investidores institucionais acima explorada. Confirma-se, assim, a evidência levantada por Bushee (1998, 2001), Brossard et al. (2013), Katan e Mat Nor (2015) e Kim et al. (2017), cujos trabalhos também destacaram a importância de se diferenciar tais agentes a partir, especialmente, da estabilidade das posições e do tamanho da participação acionária. Explicita-se, assim, a necessidade de diferenciar tais investidores ao avaliar o impacto da sua participação nas diversas decisões corporativas, bem como em seu desempenho.

Quadro 2 - Resumo dos resultados encontrados na pesquisa

\begin{tabular}{|c|c|c|c|}
\hline Cluster & Variável & Características & Perfil do investimento \\
\hline 1 & $I I_{1}$ & $\begin{array}{l}\text { Internacional } \\
\text { Público e privado } \\
\text { Dependente }\end{array}$ & $\begin{array}{l}\text { - Posição: pequena } \\
\text { - Portfólio: diversificado } \\
\text { - Estabilidade: baixa } \\
\text { - Influência marginal: alta }\end{array}$ \\
\hline 2 & $I I_{2}$ & $\begin{array}{l}\text { Internacional } \\
\text { Privado } \\
\text { Independente }\end{array}$ & $\begin{array}{l}\text { - Posição: intermediária } \\
\text { - Portfólio: menos diversificado } \\
\text { - Estabilidade: baixa } \\
\text { - Influência marginal: alta }\end{array}$ \\
\hline 3 & $\mathrm{II}_{3}$ & $\begin{array}{l}\text { Nacional } \\
\text { Privado } \\
\text { Independente }\end{array}$ & $\begin{array}{l}\text { - Posição: intermediária } \\
\text { - Portfólio: pouco diversificado } \\
\text { - Estabilidade: baixa } \\
\text { - Influência marginal: baixa }\end{array}$ \\
\hline 4 & $\mathrm{II}_{4}$ & $\begin{array}{l}\text { Nacional } \\
\text { Público e privado } \\
\text { Dependente }\end{array}$ & $\begin{array}{l}\text { - Posição: grande } \\
\text { - Portfólio: diversificado } \\
\text { - Estabilidade: alta } \\
\text { - Influência marginal: baixa }\end{array}$ \\
\hline
\end{tabular}

Fonte: elaboração própria a partir dos resultados da análise de cluster.

A Figura 2, obtida por meio da aplicação de um algoritmo não linear para redução da dimensionalidade (Maaten e Hinton 2008), ilustra os clusters identificados. É possível visualizar que alguns agentes não pareceram se adequar perfeitamente aos clusters definidos, estando todos situados entre o Cluster 4 - lilás - e o Cluster - 1 - vermelho. Entre tais agentes estão os principais fundos de pensão de empresas públicas nacionais. De fato, se definidos cinco clusters, um deles concentra a maioria destes agentes. 


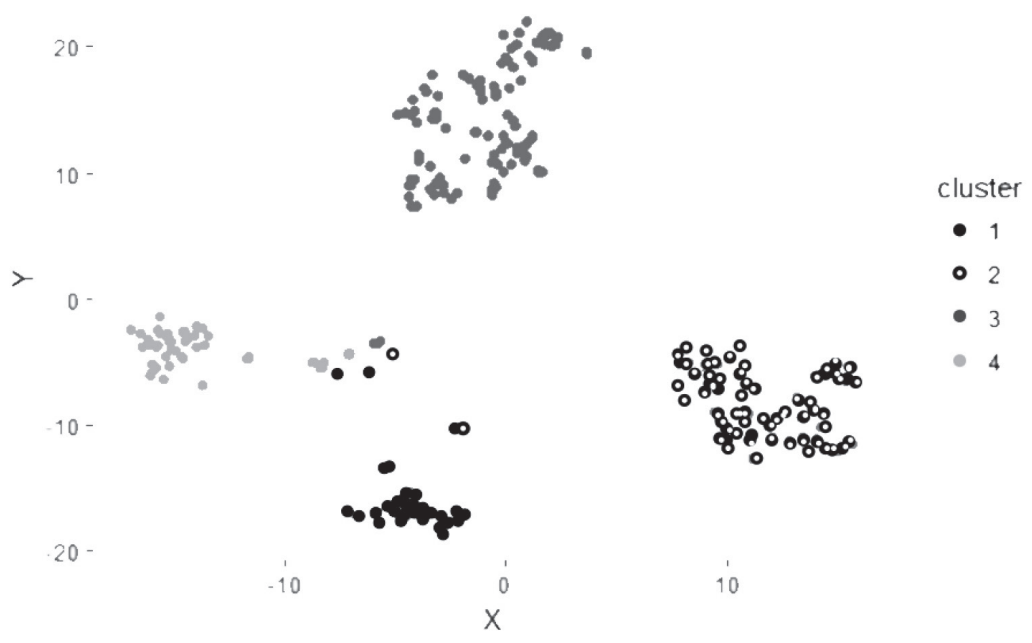

Figura 2 - Incorporação estocástica de vizinhos $t$-distribuída (t-SNE)

Fonte: elaboração própria a partir dos resultados da análise de cluster.

Neste sentido, uma preocupação associada à implementação da análise de clusters é assegurar que as informações estejam devidamente agrupadas, evitando o estabelecimento de padrões aleatórios. Para garantir que este problema não ocorresse, aplicou-se um procedimento de avaliação dos resultados do algoritmo, chamado validação. Em particular, utilizou-se uma medida de validação interna chamada Silhouette coefficient $(S)$ de forma a verificar quão similar uma observação é do seu próprio cluster em comparação ao cluster mais próximo. Pelos resultados apresentados no Anexo 4, a média do coeficiente da amostra, assim como a do de cada cluster, foi positiva e suficientemente elevada. A verificação do coeficiente por observação também comprovou não haver nenhum agente com $S$ negativo, indicando que todos os investidores foram classificados no cluster correto. Ou seja, a medida de validação utilizada corrobora a adequada classificação dos investidores institucionais. 


\section{Conclusões}

Há uma escassez de estudos empíricos que abranjam informações detalhadas sobre o portfólio e perfil de investimento dos investidores institucionais atuantes em economias emergentes, em particular, no mercado acionário brasileiro. Desse modo, esta pesquisa contribui para a literatura sobre o tema ao investigar quem são os investidores institucionais atuantes no âmbito corporativo nacional com o propósito de questionar o grau de heterogeneidade desses agentes a partir de suas principais características e perfil de investimento. Por tais motivos, figura como uma referência preliminar para outras pesquisas sobre o tema, que visem incorporar a heterogeneidade dos investidores institucionais em análises relativas, por exemplo, à potencial influência exercida por estes agentes sobre as políticas de investimento, payout, desempenho e responsabilidade social corporativa. Assim, torna-se possível questionar que tipo de investidor provê um capital com perfil de mais longo prazo ou quais investidores pressionam a gestão com base em métricas de retorno curto prazistas.

Os resultados apontaram a existência de quatro diferentes grupos de investidores institucionais atuantes como acionistas de CNF brasileiras. Tais grupos foram formados por asset managers, fundos de pensão e seguradoras, corroborando a heterogeneidade intragrupo e, portanto, a necessidade de que informações outras, que não somente as classificações gerais, delimitadas a priori, sejam consideradas pela metodologia de agrupamento.

O fato do investidor ser privado ou estatal, dependente ou independente e nacional ou estrangeiro exerceu bastante influência no perfil do investimento e, consequentemente, no agrupamento. Enquanto os Clusters 1 e 2 foram compostos por investidores internacionais, os Clusters 3 e 4 foram ambos formados por investidores brasileiros. Por outro lado, os clusters que concentraram os investidores estatais foram o $1 \mathrm{e}$, principalmente, o 4 , enquanto os Clusters 2 e 3 foram formados por investidores privados e independentes.

Os investidores internacionais agrupados nos Clusters 1 e 2 caracterizaram-se pela baixa estabilidade e maior influência marginal. Estes últimos clusters agruparam, portanto, investidores usualmente caracterizados como curto-prazistas. As diferenças entre eles residiram no fato de os investidores do Cluster 1 assumirem posições menores, associadas à maior diversificação do portfólio. O Cluster 3 demonstrou-se similar ao Cluster 2 no que 
tange aos fatores estabilidade e diversificação, sendo também composto por investidores privados e independentes. No entanto, os investidores agrupados no Cluster 3, além de serem todos nacionais, assumiram posições relativamente maiores, apresentando menor influência marginal. Finalmente, o comportamento dos investidores reunidos no Cluster 4, também formado por investidores nacionais, predominantemente estatais, foi caracterizadamente conservador e, portanto, com um potencial perfil de mais longo prazo. Em suma, os investidores dos clusters 1 e 2 são caracterizadamente curto-prazistas - ou seja, tendem a apresentar certa miopia em relação aos retornos sobre o investimento, sendo aqueles do cluster 1 mais propensos a uma maior diversificação do portfólio. Por outro lado, os investidores dos clusters 3 e 4 são mais conservadores e com perfil de mais longo prazo, sendo o cluster 3 formado por investidores nacionais e o cluster 4 por investidores nacionais e estatais.

O estudo apresenta algumas limitações. Em primeiro lugar, como argumentado por Çelik e Isaksson (2013), são inúmeras as características que, em conjunto, constituem o "modelo de negócios" de cada investidor e, por isso, orientam a sua atuação. Há, assim, critérios relevantes para diferenciar os investidores institucionais que não foram considerados nesta pesquisa, como, por exemplo, a finalidade da instituição, estrutura de passivos, objetivos políticos e sociais e regras atuariais específicas de determinados grupos. A razão para não se considerar tais aspectos reside no fato de estes serem, em sua maioria, de cunho qualitativo, sendo dificilmente replicáveis para grandes amostras.

Outra limitação é a não incorporação de critérios tais quais a forma como é cobrada a taxa de administração de certo fundo, se fixa ou sobre os rendimentos, e o fato de um fundo de pensão ser aberto ou fechado. Neste caso, a dificuldade também está em captar informações específicas sobre os investidores. Tais aspectos, se relevantes na tomada de decisão pelos gestores, fizeram com que fundos por eles geridos pertencessem a clusters diferentes a depender do perfil de investimento, caso contrário, não influenciaram o método de agrupamento adotado.

Pesquisas futuras podem abarcar diferenças institucionias e regulatórias entre os investidores atuantes no mercado acionário brasileiro, assim como analisar todo o portfólio dos investidores institucionais, incluindo investimentos internacionais e em outros títulos que não ações. Preencher essa lacuna demonstra-se particularmente relevante uma vez que possibilitaria 
realizar inferências a respeito das mudanças no perfil de ativismo de cada investidor a depender do tipo de título, além de comparar os perfis em diferentes países onde o investimento é realizado. Não obstante, é possível desenvolver uma discussão pormenorizada das questões regulatórias previstas para cada cluster de investidores institucionais identificados, discutindo tanto a sua adequação quanto as diferenças regulamentares referentes à atuação, no mercado de capitais, de cada grupo de investidores.

\section{Referências}

Bebchuk, L.; Brav, A.; Wei, J. 2015. “The long-term effects of hedge fund activism.” Columbia Law Review 115: 1085-1156.

Bena, J; Ferreira, M. A.; Matos, P.; Pires, P. 2016. "Are foreign investors locusts? The long-term effects of foreign institutional ownership.” European Corporate Governance Institute, Finance Working Paper no. 468.

Black, B. S.; Carvalho, A. G.; Gorga, E. 2008. "An overview of Brazilian corporate governance.” Cornell Law Faculty Publications Paper no. 101.

Brickley, J. A.; Lease, R. C.; Smith, C. W. 1998. "Ownership structure and voting on anti-takeover amendments.” Journal of Financial Economics 20: 267-291.

Brossard, O.; Lavigne, S.; Sakinç, M. E. 2013. “Ownership structures and R\&D in Europe: The good institutional investors, the bad and ugly impatient shareholders.” Industrial and Corporate Change 22 (4): 1031-1068.

Bushee, B. J. 1998. "The influence of institutional investors on myopic R\&D investment behavior." The Accounting Review 73 (3): 305-333.

Bushee, B. J. 2001. "Do Institutional investors prefer near-term earnings over long-run value?” Contemporary Accounting Research 18 (2): 207-46.

Bushee, B. J. 2004. "Identifying and Attracting the "right" investors: evidence on the behavior of institutional investors." Journal of Applied Corporate Finance 16 (4): 28-35.

Çelik, S.; Isaksson, M. 2013. "Institutional investors as owners: who are they and what do they do?" $O E C D$ Corporate Governance Working Papers Working Paper no. 11.

Chen, X.; Harford, J.; LI, K. 2007. “Monitoring: Which institutions matter?” Journal of Financial Economics 86 (2): 279-305.

Colot, O.; Bauweraerts, J. 2016. "Are institutional investors beneficial to family firm performance? Evidence from the French stock exchange.” International Journal of Financial Research 7 (2): 39-52.

Crane, A. D.; Michenaud, S.; Weston, J. P. 2016. "The effect of institutional ownership on payout policy: evidence from index thresholds." Review of Financial Studies 29 (6): 1377-1408.

Crotty, J. 2002. "The effects of increased product market competition and changes in financial markets on the performance of nonfinancial corporations in the neoliberal era." Political Economy Research Institute Working Paper no. 44.

Eriksen. K. W.; Kvaløy, O. 2010. “Myopic investment management.” Review of Finance 14 (3): 521-542.

Ferreira, M. A.; Matos, P. 2008. "The colors of investors' money: The role of institutional investors around the world." Journal of Financial Economics 88 (3): 499-533. 
Figueiredo Filho, D. B.; Silva Júnior, J. A. Da. "Visão além do alcance: uma introdução à análise fatorial". Opinião Pública 16 (1): 160-185.

Fu, X.; Tang, T.; Yan, X. 2019. "Why do institutions like corporate social responsibility investments? Evidence from horizon heterogeneity.” Journal of Empirical Finance 51: 44-63.

Hair, J. F.; Black, W. C.; Babin, B. J. 2009. Multivariate data analysis: a global perspective. 7. ed. Upper Saddle River: Prentice Hall.

Johnson, R. A.; Wichern, D. W. 2013. Applied multivariate statistical analysis. 6. ed. New Jersey: Pearson Education Limited.

Katan, H.; Mat Nor, F. 2015. "Institutional ownership heterogeneity and firm performance: evidence from Malaysia." International Journal of Economics and Finance 7: 176-188.

Kim, H.; Park, K.; Roy Song, K. 2017. "Do long term institutional investors foster corporate innovation?” Accounting and Finance, in press. DOI:10.1111/acfi.12284

Kim, H.; Kim, T.; Kim, Y.; Park, K. 2018. "Do long-term institutional investors promote corporate social responsibility activities?” Journal of Banking \& Finance, in press.

Lazonick, W.; O'sullivan, M. 2000. "Maximizing shareholder value: a new ideology for corporate governance." Economy and Society 29 (1): 13-35.

Lazzarini, S. G. 2011. Capitalismo de laços. Os donos do Brasil e suas conexões. Rio de Janeiro: Elsevier.

Maaten, L. Van Der; Hinton, G. 2008. "Visualizing data using t-SNE." Journal of Machine Learning Research, 620(1): 267-84.

Maia, A. G. 2002. "Valoração de recursos ambientais." Dissertação de Mestrado, Universidade Estadual de Campinas.

Maia, A. G. 2006. "Espacialização de classes no Brasil: uma nova dimensão para análise da estrutura social.” Tese de Doutorado, Universidade Estadual de Campinas.

Miyajima, K.; Shim, I. 2014. "Asset managers in emerging market economies.” BIS Quarterly Review.

OCDE. 2014. "Are institutional investors the answer for long-term development financing?" In Development Co-operation Report 2014: Mobilising Resources for Sustainable Development, edited by OCDE, 79-89. Paris: OECD Publishing.

Orhangazi, O. 2008. "Financialization and Capital accumulation in the non-financial corporate sector: a theoretical and empirical investigation of the US economy, 1973-2004." Cambridge Journal of Economics 32 (6): 863-86.

Siffert Filho, N. 1998. "Governança corporativa: padrões internacionais e evidências empíricas no Brasil nos anos 90". Revista do BNDES: 1-23. 


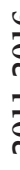

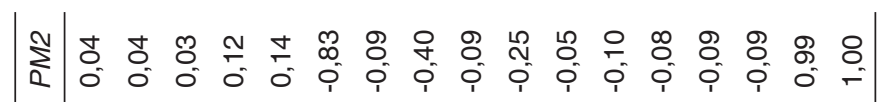

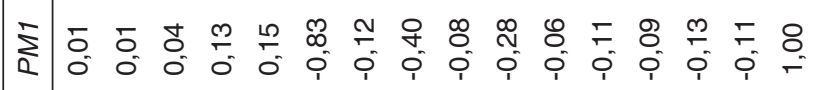

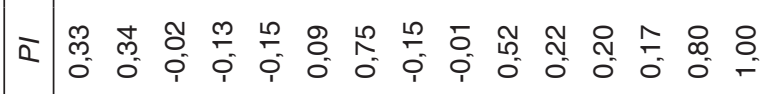

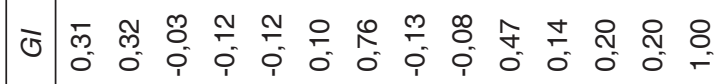

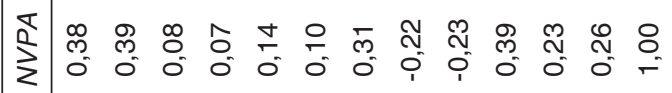

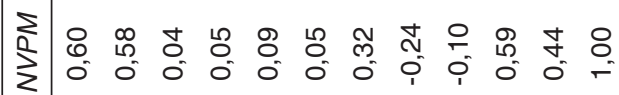

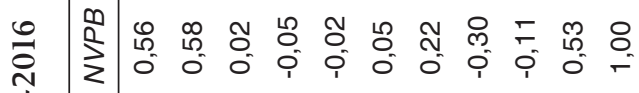

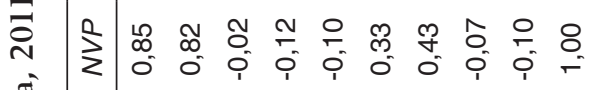

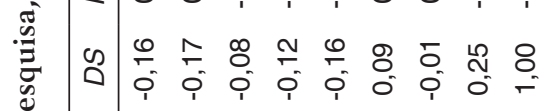

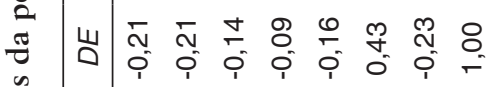

$\frac{n}{4}$

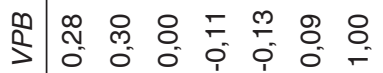

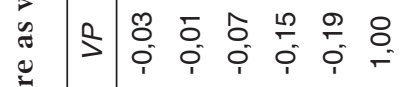

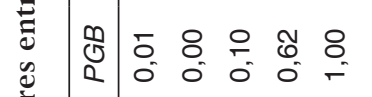

尝

苟

先

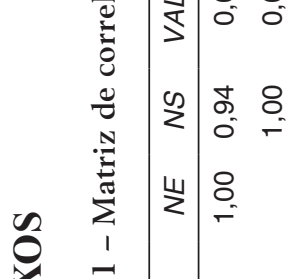

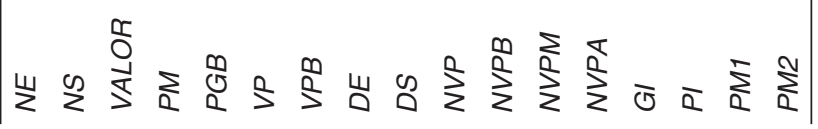

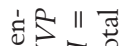

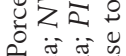

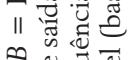

仓ิ

जै है के के

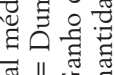

ฮี ॥

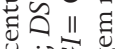

矛藏

证

递

든

래

泶 $11 \sum \frac{2}{2}$

可呵

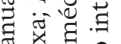

․ํㅇㅇ

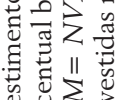

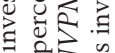

诺

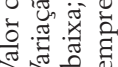

|| $\mid 1 \leq \div$

京之踏

उँचा

is 0

嵌之包

政它

응 때

政

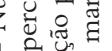

11

之.

जि

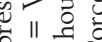

घิ \& is

记

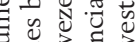


Anexo 2 - Estatísticas de adequação MSA de cada variável da pesquisa

\begin{tabular}{lc}
\hline Variável & MMA \\
\hline$N E$ & 0,7547 \\
$N S$ & 0,8393 \\
$V A L O R$ & 0,7564 \\
$P M$ & 0,6068 \\
$P G B$ & 0,6113 \\
$V P$ & 0,8082 \\
$V P B$ & 0,7747 \\
$D E$ & 0,8293 \\
$D S$ & 0,7225 \\
$N V P$ & 0,8048 \\
$N V P B$ & 0,9026 \\
$N V P M$ & 0,8396 \\
$N V P A$ & 0,7956 \\
$G I$ & 0,768 \\
$P I$ & 0,7515 \\
$P M 1$ & 0,6504 \\
$P M 2$ & 0,6483 \\
\hline
\end{tabular}

Fonte: elaboração própria a partir dos resultados da análise fatorial.

Anexo 3 - Comunalidade e especificidade de cada variável da pesquisa

\begin{tabular}{lcc}
\hline Variáveis & $\begin{array}{c}\text { Comunalidade } \\
\text { (Communality) }\end{array}$ & $\begin{array}{c}\text { Especificidade } \\
\text { (Uniqueness) }\end{array}$ \\
\hline NE & 0,8852 & 0,1148 \\
NS & 0,8778 & 0,1222 \\
VALOR & 0,1130 & 0,8870 \\
$P M$ & 0,6720 & 0,3280 \\
$P G B$ & 0,7058 & 0,2942 \\
VP & 0,8462 & 0,1538 \\
VPB & 0,8310 & 0,1690 \\
$D E$ & 0,4926 & 0,5074 \\
$D S$ & 0,2057 & 0,7943 \\
NVP & 0,8823 & 0,1177 \\
NVPB & 0,5326 & 0,4674 \\
NVPM & 0,5503 & 0,4497 \\
NVPA & 0,3697 & 0,6303 \\
$G I$ & 0,8499 & 0,1501 \\
$P I$ & 0,8374 & 0,1626 \\
$P M 1$ & 0,9340 & 0,0660 \\
$P M 2$ & 0,9334 & 0,0666 \\
\hline
\end{tabular}

Fonte: elaboração própria a partir dos resultados da análise fatorial. 
Anexo 4 - Silhouette coefficient médio de cada um dos 4 clusters definidos

\begin{tabular}{ccc}
\hline Cluster & Número de observações & Si médio \\
\hline 1 & 52 & 0,41 \\
2 & 104 & 0,60 \\
3 & 133 & 0,62 \\
4 & 57 & 0,29 \\
$1-4$ & 346 & 0,53 \\
\hline
\end{tabular}

Fonte: elaboração própria a partir dos resultados da análise de cluster. 